\title{
Marginal Adaptation Assessment for Two Composite Layering Techniques Using Dye Penetration, AFM, SEM and FTIR: An In-Vitro Comparative Study
}

\author{
Andrea Maria Chisnoiu ${ }^{1}$, Marioara Moldovan ${ }^{2}$ (D), Codruta Sarosi ${ }^{2}$, Radu Marcel Chisnoiu ${ }^{3, *}$, \\ Doina Iulia Rotaru ${ }^{3}$, Ada Gabriela Delean ${ }^{3}$, Ovidiu Pastrav ${ }^{3}$, Alexandrina Muntean ${ }^{4}$, Ioan Petean ${ }^{5}$ (D), \\ Lucian Barbu Tudoran ${ }^{6,7}$ and Mihaela Pastrav 8
}

Citation: Chisnoiu, A.M.; Moldovan M.; Sarosi, C.; Chisnoiu, R.M.; Rotaru, D.I.; Delean, A.G.; Pastrav, O.;

Muntean, A.; Petean, I.; Tudoran, L.B.; et al. Marginal Adaptation

Assessment for Two Composite Layering Techniques Using Dye Penetration, AFM, SEM and FTIR: An In-Vitro Comparative Study. Appl. Sci. 2021, 11, 5657. https://doi.org/ 10.3390/app11125657

Academic Editor: Vittorio Checchi

Received: 25 May 2021

Accepted: 15 June 2021

Published: 18 June 2021

Publisher's Note: MDPI stays neutral with regard to jurisdictional claims in published maps and institutional affiliations.

Copyright: (C) 2021 by the authors Licensee MDPI, Basel, Switzerland. This article is an open access article distributed under the terms and conditions of the Creative Commons Attribution (CC BY) license (https:/ / creativecommons.org/licenses/by/ $4.0 /)$.
1 Department of Prosthodontics, "Iuliu Hatieganu" University of Medicine and Pharmacy, 32 Clinicilor Street, 400006 Cluj-Napoca, Romania; maria.chisnoiu@umfcluj.ro

2 Department of Polymeric Composites, "Raluca Ripan" Institute of Research in Chemistry, "Babes Bolyai" University, 30 Fantanele Street, 400294 Cluj-Napoca, Romania; marioara.moldovan@ubbcluj.ro (M.M.); codruta.sarosi@ubbcluj.ro (C.S.)

3 Department of Cariology, Endodontics and Oral Pathology, "Iuliu Hatieganu" University of Medicine and Pharmacy, 33 Motilor Street, 400001 Cluj-Napoca, Romania; doina.rotaru@umfcluj.ro (D.I.R.); ada.delean@umfcluj.ro (A.G.D.); ovidiu.pastrav@umfcluj.ro (O.P.)

4 Department of Pedodontics, "Iuliu Hatieganu" University of Medicine and Pharmacy, 31 Avram Iancu Street, 400117 Cluj-Napoca, Romania; alexandrina.muntean@umfcluj.ro

5 Faculty of Chemistry and Chemical Engineering, "Babes Bolyai" University, 11 Arany Janos Street, 400028 Cluj-Napoca, Romania; ioan.petean@ubbcluj.ro

6 Electron Microscopy Centre, “Babes Bolyai” University, 5-7 Clinicilor Street, 400006 Cluj-Napoca, Romania; lucianbarbutudoran@gmail.com

7 Advanced Research and Technology Centre for Alternative Energy, National Institute for Research and Development of Isotopic and Molecular Technologies, 67-103 Donat Street, 400331 Cluj-Napoca, Romania

8 Department of Orthodontics, "Iuliu Hatieganu” University of Medicine and Pharmacy, 31 Avram Iancu Street 400117 Cluj-Napoca, Romania; mihaela.pastrav@umfcluj.ro

* Correspondence: marcel.chisnoiu@umfcluj.ro; Tel.: +40-721-207-617

Abstract: Do the new, modern dental resin composites improve the sealing in cavities restorations? The present study was designed to compare the effect of two different, but most used layering techniques of the dental composite in reducing the marginal microleakage when a brand-new material is used; Class I black cavities were prepared on 120 human extracted teeth and then restored using oblique and horizontal layering technique. The dye penetration analysis, the atomic force microscopy (AFM), scanning electron microscopy (SEM) together with energy-dispersive X-ray spectroscopy (EDX) and Fourier transform infra-red spectroscopy (FTIR) technique were used to assess the adaptation of the restorative material to the dental structures. Some better results were obtained for oblique layering technique, but the differences to the other method have not been statistically validated. The composite layering technique still remains an open quest and, moreover, in vivo studies should be designed in order to assess microleakage in real conditions of the oral environment.

Keywords: composite restoration; microleakage; oblique layering technique; horizontal layering technique

\section{Introduction}

One of the most important issues in restorative dentistry is the failure of restorative materials to completely bind to hard dental tissues, both enamel and dentin. The ability of the restoration to perfectly fit to the walls of the cavity and to seal them influences the durability of the treatment. Speaking of perfection, a firm bond between the dental tissues and the restorative material should lead to a snug and concealed marginal adaptation [1]. Despite the technological improvement, for the moment, no material perfectly adheres to 
the tooth surface. This results in cracks between the restorative material and the margins of the cavity, allowing the microleakage [2].

Microleakage is defined as the passage of bacteria, fluids, molecules or ions, between the restoration and the cavity walls. It has been considered to be involved in the development of recurrent caries, pulpal inflammation or, even the failure of the endodontic treatments [3]. The improper adaptation, the deformation due to load or temperature variations of the restorative material or the contraction during polymerization may result in gaps which will represent a pathway for bacteria and their products to the dentin and, further, to the pulp $[4,5]$.

The composite resin polymerization shrinkage may be the most important factor that leads to microleakage occurrences. Along the factors involved in shrinkage stress, there can be noticed the cavity size and geometry (including the configuration factor- $\mathrm{C}$ factor), the application technique (including composite layering and light curing) and the composite characteristics (including modulus of elasticity) [6].

Several procedures were imagined in order to solve or, at least, to improve the sealing problem of the posterior composite resin restorations. One of these procedures is represented by the oblique layering technique which involves the use of 1 to $1.5 \mathrm{~mm}$ triangle-shaped increments of resin, so the $C$ factor reduced [7]. The highest value of the $C$ factor is considered to be when the horizontal layering technique is used. This is the most easy-to-use and, probably, the most comfortable technique for the beginner practitioners.

Recent studies indicate that the most important factor in achieving a successful restoration is likely careful and proper placement and light-curing technique, independent of the placement technique [8-10]. Based on these results, the current study has been designed as an innovative and complex research to compare the effect of two different layering techniques of the dental composite in reducing of marginal microleakage, to assess the adaptation of the restorative material to the dental tissue by atomic force microscopy (AFM), to evaluate the efficacy of polymerization in composite resins by Fourier transform infra-red spectroscopy (FTIR) technique and to correlate the observations with the SEM -EDX investigation for these two techniques when using same adhesive system and same restorative material.

\section{Materials and Methods}

\subsection{Preparation of the Sample}

One-hundred-twenty teeth were included in this study, maxillary and mandibular molars and premolars, extracted due to orthodontic or periodontal reasons, no more than 4 weeks before the study. Only caries-free teeth were included in the group, without coronary destruction and without pre-existing restorations. In order to meet the hydration conditions, these teeth were preserved in distilled water [11,12].

\subsection{Cavities Preparation}

A single operator prepared a Class I black cavity on the occlusal surface of each tooth. The depth of the cavity did not exceed $3 \mathrm{~mm}$. These cavities were prepared with 0.12 round turbine burs (MDT, Mc Drill Technology, Parma, Italy) in enamel thickness and 0.14 steel round low-speed handpiece burs (Dendia, Dendia GmbH, Feldkirch, Austria) in dentin thickness, following the ditches and avoiding the cusps. A new bur was used after every 5 cavity preparations. An UNC 15 probe (Hu Friedy Mfg. Co. Inc., Chicago, IL, USA) was used for measuring the depth and the width of the cavity. No additional retentions were prepared, as the cavities were restored with adhesive materials.

\subsection{Restoration Technique}

The teeth were randomly divided into 2 groups of 60 teeth each based on the restorative layering technique as Group A-oblique layering technique, and Group B-horizontal layering technique. As an adhesive system, a 3 steps system was used, considering that this represents the golden standard in dental adhesion. For both groups (A, B), the enamel 
was etched for $30 \mathrm{~s}$ and dentin for $15 \mathrm{~s}$ using 37\% Meta Etchant Gel (Meta Biomed Co. Ltd. Osong-eup, Republic of Korea), then washed and gently dried for $5 \mathrm{~s}$. The new G2-BOND Universal (GC Europe) was used, according to the manufacturer instructions-first the Primer, for $10 \mathrm{~s}$, using a microbrush and dried for $5 \mathrm{~s}$, then the Bond, spread evenly using a gentle stream of air and light cured for $10 \mathrm{~s}$, using a LED light-curing lamp (TransluxWave, Kulzer, Germany). Teeth were then filled by a single operator, with a brand-new composite (G-aenial A'CHORD, GC Europe) using oblique layering technique (Group A) and horizontal layering technique (Group B) with $1 \mathrm{~mm}$ thick increments and light-curing for $20 \mathrm{~s}$.

The shade of the composite was different from the tooth in order to facilitate the assessment. In the end, the restorations were finished and polished with red and yellow ring burs, rubber cups, brushes and polishing paste.

\subsection{Thermocycling}

All specimens were thermocycled for 1000 cycles $\left(5 / 55^{\circ} \mathrm{C}, 30 \mathrm{~s}\right)$ in Eppendorf Mastercycler gradient (Eppendorf AG, Hamburg, Germany). Then, the surfaces of the roots were covered with two layers of nail polish and the apices were sealed with orthodontic wax. All samples were immersed in $2 \%$ methylene blue dye for $24 \mathrm{~h}$, then the teeth were washed with distilled water and dried. Then they were embedded in acrylic resin (Duracryl Plus, SpofaDental) and, later, sectioned mesio-distally using the microtome (IsoMet TM1000, Buehler, Chicago, IL, USA). There were selected those teeth slices that had no damages after cutting. Each tooth slice was $1 \mathrm{~mm}$ thick.

For marginal microleakage assessment, the cut sections were observed under $20 \times$ magnification and the area of maximum dye penetration was considered. For the magnification, a stereomicroscope was used (Zeiss CL 1500 ECO) and each sample was photographed using a digital photo camera (Canon EOS 1300D).

Two examiners scored the extent of dye penetration using a scale (0-4) by consensus. Examiners were blind to the technique used.

The scoring criteria [13]:

0 - no evidence of dye penetration;

1 -dye penetration along the axial cavity walls up to $1 / 3$;

2 -dye penetration along the axial cavity walls up to $2 / 3$;

3 -dye penetration along the whole axial cavity wall;

4 -dye penetration on the pulpal wall.

The AFM analysis was conducted on the composite resin (restorative material) for both groups as well as the correspondent interfaces with enamel and dentine. The AFM images were obtained in tapping mode with a JEOL JSPM 4210 Scanning Probe Microscope, produced by JEOL, Japan, Tokyo. The cantilevers used are NSC 15 type produced by MicroMasch, Estonia, Talinn, having a resonant frequency of about $325 \mathrm{kHz}$ and a force constant of $40 \mathrm{~N} / \mathrm{m}$. The images were scanned at area of $5 \mu \mathrm{m} \times 5 \mu \mathrm{m}$ for the restorative material and at $20 \mu \mathrm{m} \times 20 \mu \mathrm{m}$ for the interfaces. At least 3 different macroscopic areas were scanned for each situation. All images were processed in standard manner using Jeol WIN SPM 2.0 processing soft, the average roughness ( $\mathrm{Ra}$ ) and the root mean squared roughness $(\mathrm{Rq})$ being measured for each image.

The samples for scanning electron microscopy (SEM) were prepared as well as for light microscopy, in order to investigate the enamel-composite and dentin-composite interfaces and the structure of the enamel and dentin. High-resolution scanning electron microscopy (HR-SEM) and energy-dispersive X-ray spectroscopy (EDX) were conducted on a Hitachi SU8230 cold field emission scanning electron microscope. Samples were subsequently sputter-coated with an $\sim 7 \mathrm{~nm}$ thick layer of gold and imaged under $30 \mathrm{kV}$ acceleration voltage.

For FTIR analysis, a spectrometer (Jasco 610, Jasco International Co., Ltd., Tokyo, Japan) in an ATR mode was used, with a scanning range from 4000 to $550 \mathrm{~cm}^{-1}$ at a speed of $4 \mathrm{~cm} / \mathrm{s}$ and with an average of 128 measurements in the final spectrum. 


\subsection{Statistical Analysis}

Before statistical analyses, G3*Power calculation (software version 3.1.9.6, Erdfelder, Faul and Buchner, 1996, Heinrich Heine University, Dusseldorf, Germany) was used to identify the adequate number of samples to be included in the study. Considering similar studies, the expected mean values of scores were around 2 and standard deviations around 0.9 [14]. These data indicated an estimated effect size that was used to calculate minimal necessary number of samples for analysis of variance. All data were collected and statistically analyzed using SPSS Statistics (ver. 20.0, IBM, Chicago, IL, USA). The Kruskal-Wallis test followed by the Mann-Whitney $\mathrm{U}$ test were used and $p$ values $<0.05$ were considered statistically significant.

\section{Results}

\subsection{Microleakage Assesment}

The dye penetration varied from Score 0 to Score 4 for both groups, but lower scores were obtained for Group A than Group B (Figures 1 and 2).
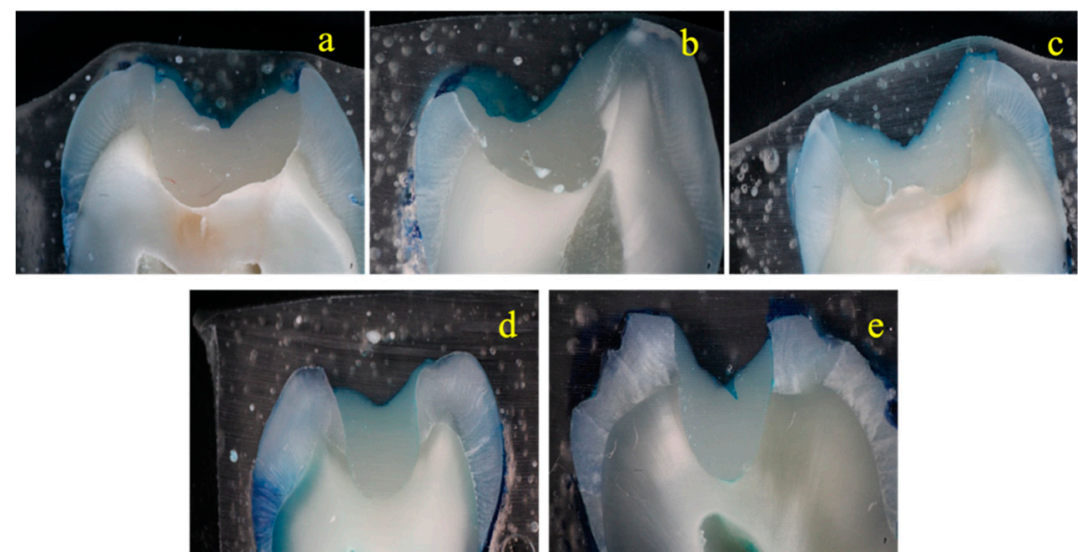

Figure 1. Microleakage scoring: (a) Score 0; (b) Score 1; (c) Score 2; (d) Score 3; (e) Score 4.

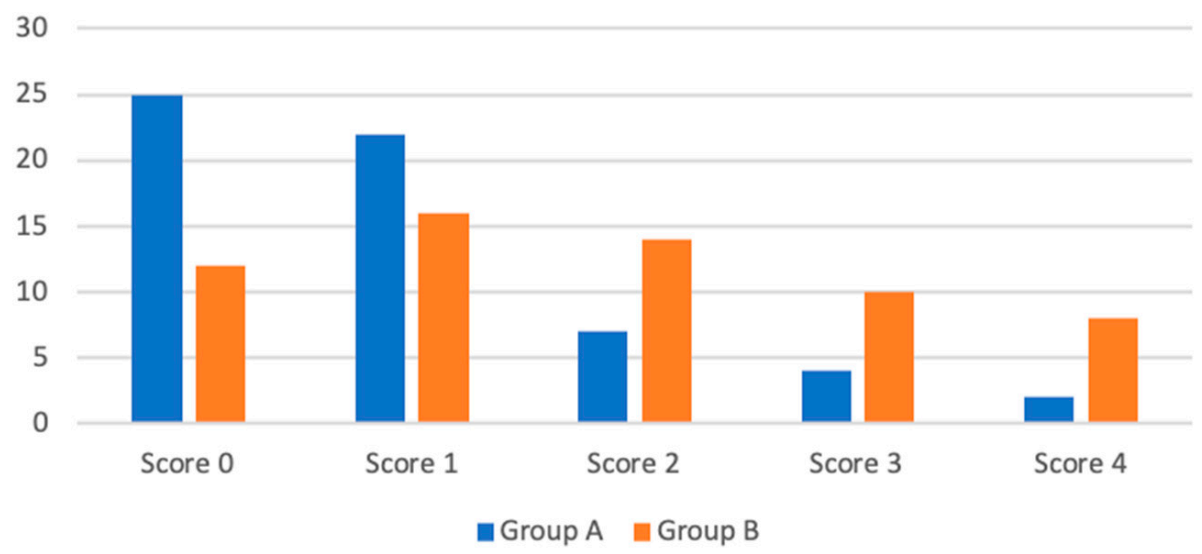

Figure 2. Oblique and horizontal layering technique scoring distribution.

All collected data after scoring were subjected to statistical analysis within the limitations of this study. The mean value in Group A was lower than in Group B. Although there were differences in the results in the two groups, they were not statistically validated $(p>0.05)($ Table 1$)$. 
Table 1. Microleakage in the oblique (Group A) and horizontal (Group B) layering technique.

\begin{tabular}{cccc}
\hline Microleakage & Mean & Standard Deviation & $p$-Value \\
\hline Group A & 1 & 1.1427 & 0.723 \\
Group B & 2 & 1.3304 & \\
\hline
\end{tabular}

\subsection{Atomic Force Microscopy Analysis}

For Group A, the fine microstructure of the Composite (C) is presented in Figure 3a. The topographic image reveals a scaly morphology. It is formed up by some submicron boulders (having diameter around $600 \mathrm{~nm}$ ) very well bonded together with a nanostructured material which is formed by well stacked nanoparticles of about $60 \mathrm{~nm}$. Overall, in Group A, the restorative material proves to be very compact assuring an optimal bulk filling of the cavity. The tri-dimensional image shows a relatively smooth surface having a Ra $=45.6$ and $\mathrm{Rq}=57.9$. Fact deals within the high level of compactness inside of the material.

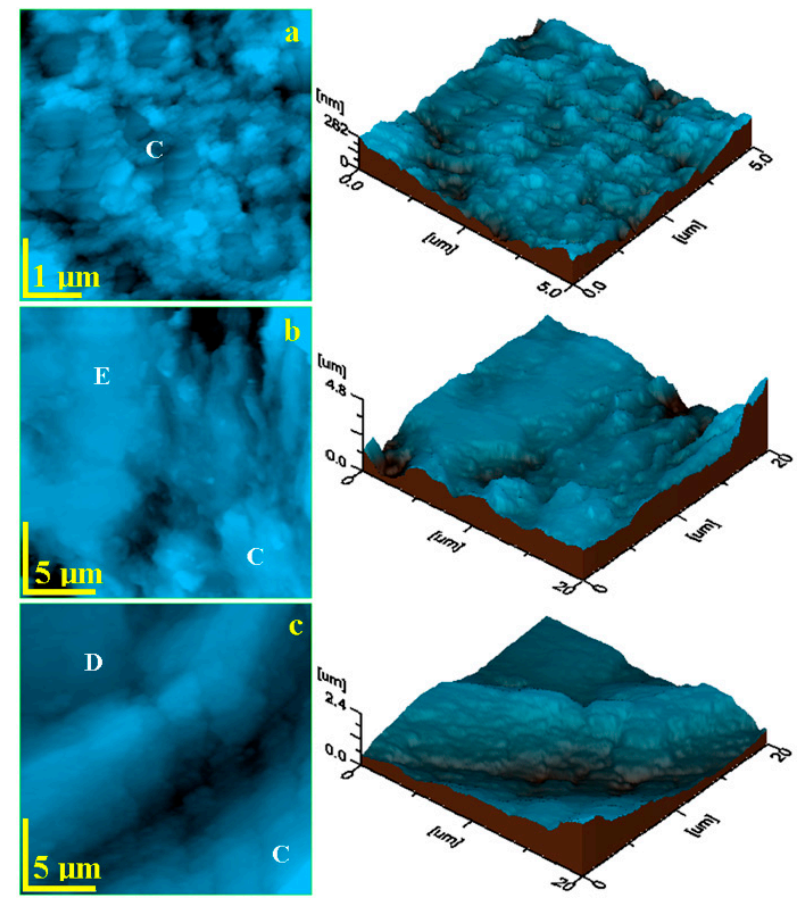

Figure 3. AFM 2D topographic images for Group A samples: (a) composite (restorative material), (b) composite—enamel interface, and (c) composite-dentin interface. Tri-dimensional images are given next to 2D topographic images. C-composite, E-enamel, D-dentin.

The composite-enamel (C-E) interface is presented in Figure 3b. The left side of the topographic image is the enamel featuring a smooth and very compact surface and the right side of the image belongs to composite. Its morphology is similar with the one observed in Figure 3a. The middle vertical of the image in Figure $3 \mathrm{~b}$ represents the interface. It features a very compact structure with less presence of submicron formation but richest in nanostructured compound which is very well attached to the hydroxyapatite nanoparticles within the enamel. The interface is more visible in the tri-dimensional image as a gap filled with a compact material which assures a strong cohesion between restorative material and enamel. The average thickness of the bonding layer is about of $5 \mu \mathrm{m}$. The presence of the bonding interface between composite and enamel leads to a surface roughness increasing of Ra to $315.25 \mathrm{~nm}$ and $\mathrm{Rq}$ to $412.0 \mathrm{~nm}$ (Table 2). 
Table 2. Roughness values for the Group A sample.

\begin{tabular}{|c|c|c|c|c|}
\hline \multicolumn{2}{|c|}{ Roughness } & \multirow{2}{*}{$\begin{array}{c}\text { Mean Value } \\
45.6\end{array}$} & \multirow{2}{*}{$\frac{\text { Standard Deviation }}{13.923}$} & \multirow{2}{*}{$p$-Value } \\
\hline \multirow{3}{*}{$\mathrm{Ra}$} & C & & & \\
\hline & $\mathrm{C}-\mathrm{E}$ & 315.25 & 31.063 & \multirow[b]{2}{*}{0.093} \\
\hline & C-D & 240.25 & 98.63 & \\
\hline \multirow{3}{*}{$\mathrm{Rq}$} & $\mathrm{C}$ & 57.9 & 17.583 & \multirow{3}{*}{0.184} \\
\hline & C-E & 412.0 & 35.655 & \\
\hline & C-D & 300.75 & 119.226 & \\
\hline
\end{tabular}

The composite-dentine (C-D) interface is observed by AFM in Figure $3 c$ on the diagonal from left down corner to the right upper corner, the dentine appears on the left upper corner and composite on the right lower corner. The adhesion layer also has a thickness of about $5 \mu \mathrm{m}$ and is filled up with fine nanostructured bonding material which assures a very good adhesion of the restorative material to the hydroxyapatite nanoparticles from the dentin structure. The tri-dimensional image features the adhesion layer as a wellformed furrow along to the interface proving the strong cohesion between restoration material in Group A sample and dentine. The smoothness of the bonding observed in this case leads to a less increased roughness: $\mathrm{Ra}$ to $240.25 \mathrm{~nm}$ and $\mathrm{Rq}$ to $300.75 \mathrm{~nm}$ (Table 2).

Although $\mathrm{Ra}$ and $\mathrm{Rq}$ values are higher for $\mathrm{C}-\mathrm{E}$ interface than $\mathrm{C}-\mathrm{D}$, the differences are not statistically significant $(p>0.05)$.

For Group B, Composite (C) has a particular morphology as seen in the topographic image in Figure 4a. It is based on a submicron granular material with boulder aspect and diameters varying in a wide range between 200 to $500 \mathrm{~nm}$ consolidated in a compact block with a nanostructured material having fine rounded units with diameter of about $80 \mathrm{~nm}$. Such compact area is observed in the upper side of the topographic image in Figure 4a. The lower side of the image features a pore occurred in the restorative material having a diameter of about $1.3 \mu \mathrm{m}$ and a dendritic-irregular border. The pore is formed in the boulder reach areas, perhaps due to a local lack of nanostructured material. Overall, the composite assures a good in bulk filling of the cavity and features a good cohesion despite the observed pores.

The topographic image in Figure $4 \mathrm{~b}$ captures the interface between enamel (E) (low side of image) and Composite (C) in the upper side of the image. The enamel area is very smooth and compact corresponding to a perfectly healthy state. The $\mathrm{C}$ features two pores with prolonged aspect and irregular borders nearby the interface. The nanostructured material within $C$ perfectly seals those pores and assures an optimal cohesion with the enamel. The bonding layer is difficult to be observed because of the great adhesion to the enamel. The tri-dimensional image allows us to establish the adhesion layer thickness of about $4 \mu \mathrm{m}$. The pores presence nearby the interface leads to a surface roughness increasing, presented in Table 3.

The interface $\mathrm{C}-\mathrm{D}$ is more evident as a gap between dentine to the left and composite to the right in the topographic image, Figure 4c. The gap width is about $3 \mu \mathrm{m}$ and is completely filled with nanostructured bonding material. A strong cohesion is observed on the both sides, a fact also depicted by the tri-dimensional image. The smoothness observed along the $\mathrm{C}-\mathrm{D}$ interface leads to a smaller increasing of the roughness. The fact deals with the pore lack nearby dentine.

The Ra and Rq values are higher for C-E interface than C-D, similar to Group A, but the differences are not statistically significant.

Comparing the roughness between the two groups, it results a similar variation for both C-E and C-D interfaces and no statistical difference was validated (Table 4). 

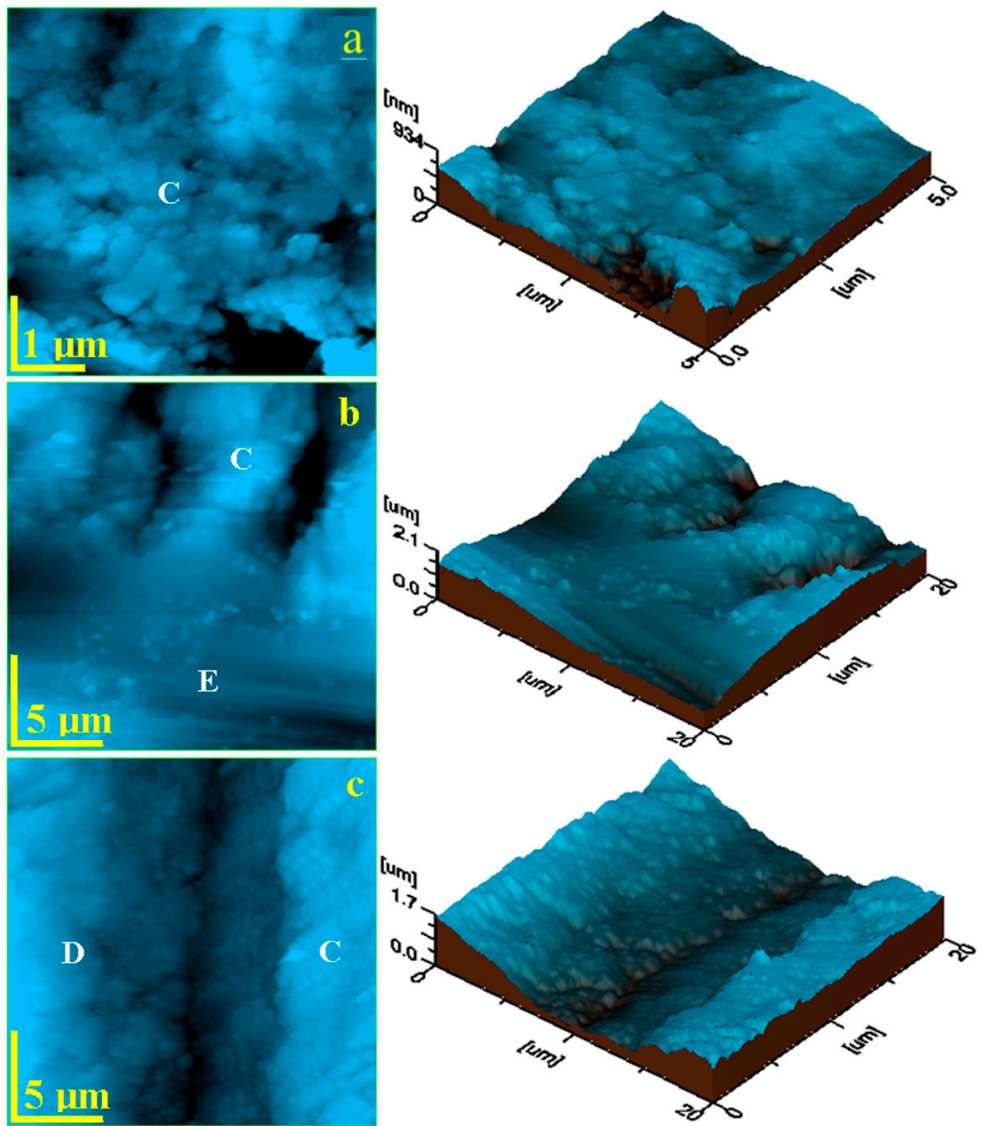

Figure 4. AFM 2D topographic images for Group B samples: (a) composite (restorative material), (b) C-E interface, and (c) C-D interface. Tridimensional images are given next to 2D topographic images.

Table 3. Roughness values for the Group B sample.

\begin{tabular}{|c|c|c|c|c|}
\hline \multicolumn{2}{|c|}{ Roughness } & \multirow{2}{*}{$\begin{array}{c}\text { Mean Value } \\
49.83\end{array}$} & \multirow{2}{*}{$\begin{array}{c}\text { Standard Deviation } \\
8.857\end{array}$} & \multirow[t]{2}{*}{$p$-Value } \\
\hline \multirow{3}{*}{$\mathrm{Ra}$} & $\mathrm{C}$ & & & \\
\hline & $\mathrm{C}-\mathrm{E}$ & 318.75 & 139.047 & \multirow[t]{2}{*}{0.063} \\
\hline & C-D & 253.0 & 88.185 & \\
\hline \multirow{3}{*}{$\mathrm{Rq}$} & $\mathrm{C}$ & 67.86 & 11.850 & \multirow{3}{*}{0.058} \\
\hline & $\mathrm{C}-\mathrm{E}$ & 411.75 & 188.032 & \\
\hline & C-D & 309.25 & 91.729 & \\
\hline
\end{tabular}

Table 4. Roughness values for the Group A and B samples.

\begin{tabular}{|c|c|c|c|c|c|}
\hline & Roughness & & Mean Value & Standard Deviation & $p$-Value \\
\hline \multirow{4}{*}{ Ra } & \multirow{2}{*}{ C-E } & Group A & 315.25 & 31.063 & \multirow{2}{*}{0.294} \\
\hline & & Group B & 318.75 & 139.047 & \\
\hline & \multirow{2}{*}{ C-D } & Group A & 240.25 & 98.63 & \multirow{2}{*}{0.162} \\
\hline & & Group B & 253.0 & 88.185 & \\
\hline \multirow{4}{*}{$\mathrm{Rq}$} & \multirow{2}{*}{ C-E } & Group A & 412.0 & 35.655 & \multirow{2}{*}{0.091} \\
\hline & & Group B & 411.75 & 188.032 & \\
\hline & \multirow{2}{*}{ C-D } & Group A & 300.75 & 119.226 & \multirow{2}{*}{0.087} \\
\hline & & Group B & 309.25 & 91.729 & \\
\hline
\end{tabular}




\subsection{Scanning Electron Microscopy (SEM) and Energy-Dispersive X-ray Spectroscopy (EDX) Analysis}

The SEM analysis was performed in order to observe the adhesion between the restoration material and the dental tissues when there was no dye penetration (scores $=0$ ) as well as when the dye penetrated the composite/dental tissue interface (scores $>0$ ).

Analysing the Score 0 samples, adhesive interfaces completely adapted to the restoration material were observed. SEM images show a uniform and efficient polymerization on the entire restored cavity. The hybrid layer has a thin, homogeneous and denser structure in electrons with a relatively uniform thickness $(\sim 2 \mu \mathrm{m})$, which closely followed the tooth surface and formed a hybrid layer penetrating the thickness of the dental tissue, in some cases on a depth of $10 \mu \mathrm{m}$. The high degree of homogeneity of the polymerized adhesive layer was also noticed. It was observed that the resin extensions, which intersect the hybrid layer, have an electronic density similar to the overlying adhesive layer, which demonstrated a continuity of the nanoparticle concentration into depth. Thus, the periphery of the dental tissue was also hybridized and the hybrid layer extends in the entire depth of the demineralized area (Figures 5 and 6).
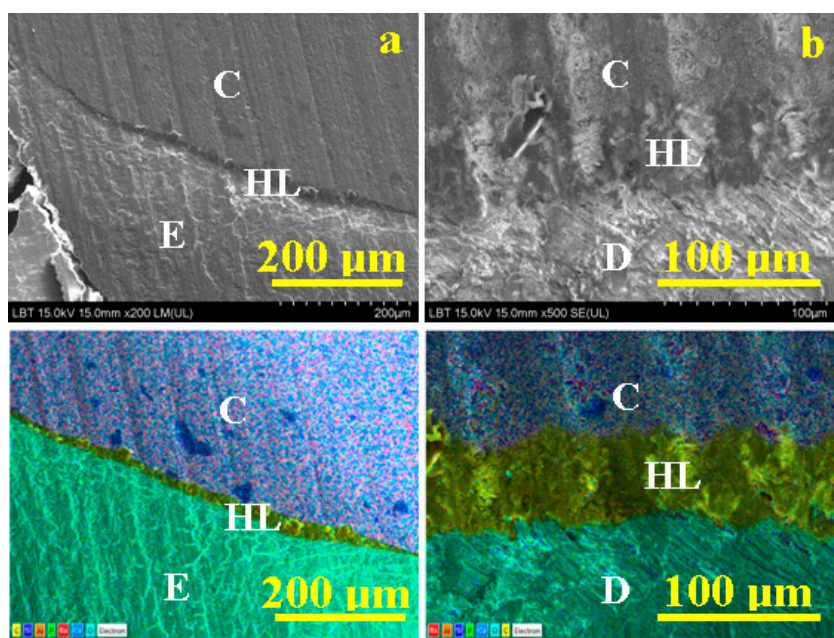

Figure 5. SEM images for Score 0 in Group A: (a) Composite (C)—enamel interface (E); (b) Composite (C) — dentin (D) interface; HL—hybrid layer. EDX mappings are given below for each SEM electron image.

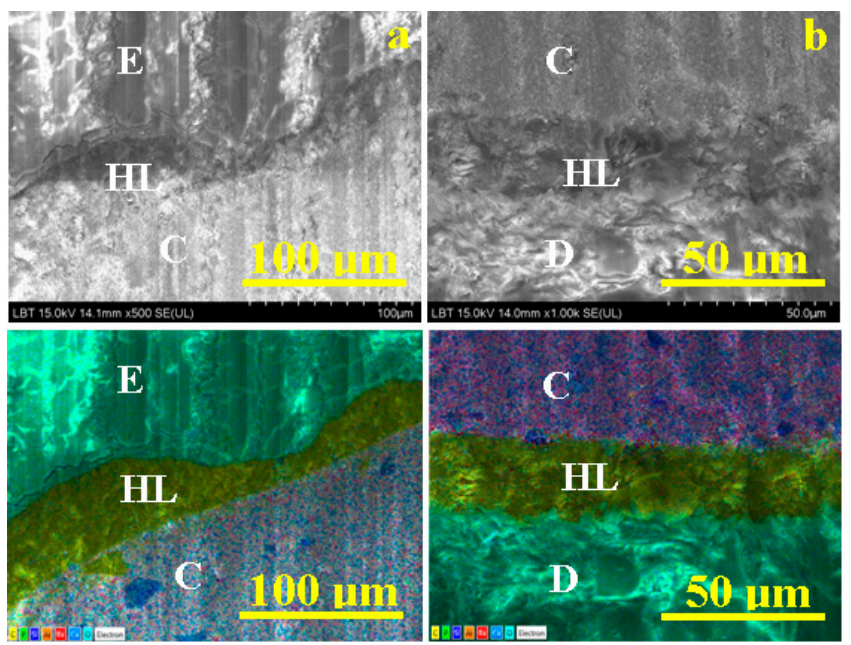

Figure 6. SEM images for Score 0 in Group B: (a) Composite (C)—enamel interface (E); (b) Composite (C)—dentin (D) interface; HL—hybrid layer. EDX mappings are given below for each SEM electron image. 
Regarding the samples with a score higher than 0 , there can be noticed cracks at the dental tissue/hybrid layer or composite/hybrid layer interfaces, with a varying length for different samples. Gaps and fissures were observed at the composite/dentin interface more than at the composite/enamel interface, indicating that the adhesion to the dentin is likely to be influenced by several factors than the enamel (Figure 7).
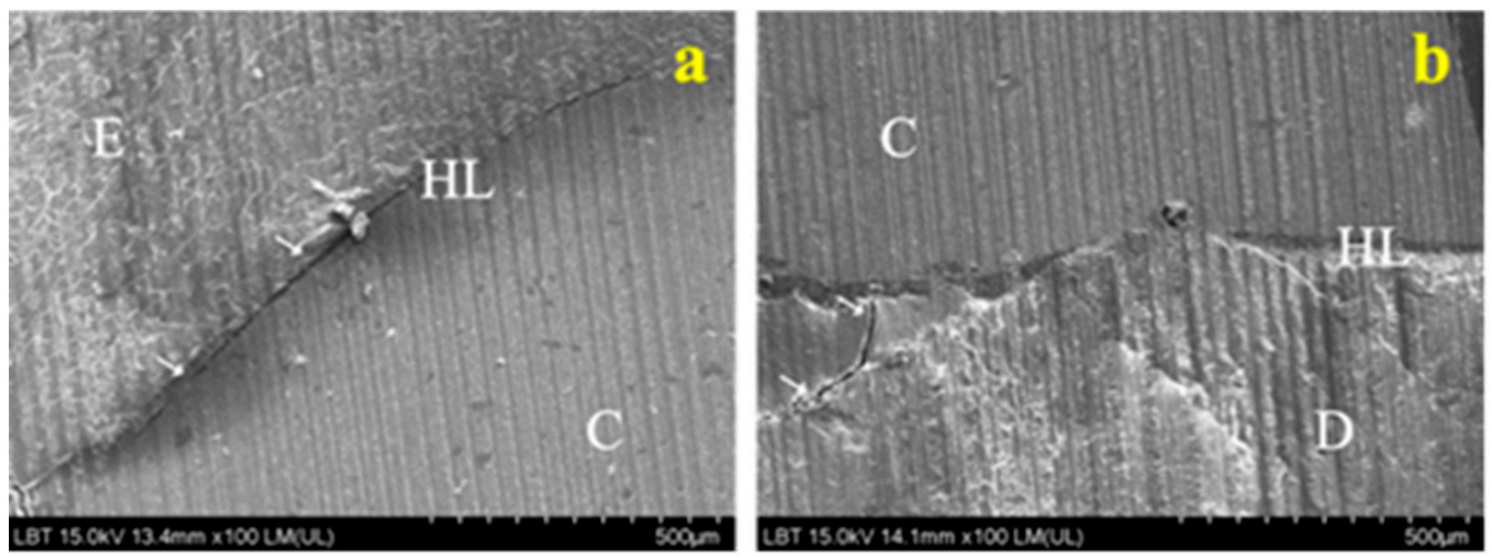

Figure 7. SEM images for Score 3: (a) Composite (C)—enamel interface (E); (b) Composite (C)—dentin (D) interface; HL-hybrid layer.

The EDX images indicate a high content of atomic oxygen $(\mathrm{O})$, calcium $(\mathrm{Ca})$, silica $(\mathrm{Si})$, carbon $(\mathrm{C})$ and phosphorus $(\mathrm{P})$ and a medium content of barium $(\mathrm{Ba})$. The analysis indicated a high concentration of phosphorus and calcium in dentin which suddenly drops at the dentin/composite interface. Regarding the adhesive layer, an increase in carbon was observed for all samples, suggesting that the monomers contained that element. In addition, the images revealed small concentrations of aluminum and silica in dentin as well as in the adhesive layer.

\subsection{Fourier Transform Infra-Red Spectroscopy (FTIR)}

The intensity of the peak at $995 \mathrm{~cm}^{-1}$ associated with PO from apatite, the majority component of enamel and dentin, is highlighted (Figure 8). The weak bands of 1214 and $1455 \mathrm{~cm}^{-1}$ are attributed to the organic components of dentin (dentinal collagen).

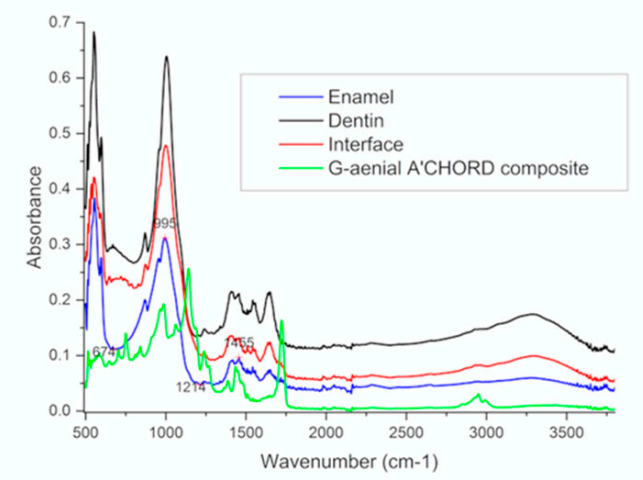

b

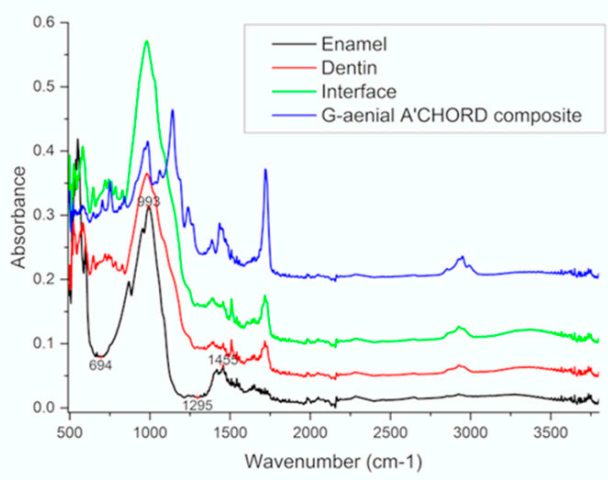

Figure 8. FTIR spectrum based on the restorative layering technique: (a)- oblique layering technique; (b)- horizontal layering technique.

The IR spectrum corresponding to the adhesive intertubular interface infiltrated in demineralized dentin highlights together with the characteristic bands of apatite $\sim 950 \mathrm{~cm}^{-1}$ and dentinal collagen $1637 \mathrm{~cm}^{-1}(\mathrm{CC}), 1455 \mathrm{~cm}^{-1}\left(\mathrm{CH}_{2}\right)$, specific bands of the monomer mixture at $1719 \mathrm{~cm}^{-1}$ (specific for urethane carbonyl), $2870-2965 \mathrm{~cm}^{-1}\left(\mathrm{CH}_{2}\right.$ from the 
structure of the urethane monomer), as well as the $638 \mathrm{~cm}^{-1}$ band attributed to the aromatic cycle in Bis-GMA.

The intensity of the bands associated with the Bis-MEPP monomer from composite resin composition suggest that the monomer resin diffuses deeply in the demineralized area of the dentin, meaning the affinity of the monomer to the dental structure.

\section{Discussion}

It is a continuous quest for the perfect restorative material and restoration technique that ensure the ideal adherence to the tooth surface for eliminating the microleakage. It is, also, very important to maintain the marginal seal in time and to minimize the clinical issues due to microleakage, like marginal discolorations or recurrent caries [15].

The ability of restorative material to reduce the microleakage along the restauration/dental wall interface is crucial in its clinical success. There are several methods that have been proposed in order to assess the correctness of a restoration and the degree of microleakage alongside the margins. One of the most used methods is the dye diffusion. This method involves the use of different dyes like methylene blue, eosin, aniline blue, Indian ink or fluorescein [16].

It is important to mention that the diameter of the dye particles should be smaller than the diameter of dentinal tubules $(1-4 \mu \mathrm{m})$, otherwise they might be retained by the dental structures or the restorative material, representing a source of errors. According to other dye penetration studies, it is recommended to use a dye with a particle diameter equal to the bacterial size or smaller $(\sim 2 \mu \mathrm{m})$ [17]. For this reason, in this study methylene blue solution was used as a dye, since its particle size is smaller than bacteria $\left(1.2 \mathrm{~nm}^{2}\right)$ [18].

Microleakage that occurs along the restorative material/dental tissue interface is the most important issue when composite resins are used for restorations. In order to reduce the shrinkage associated with resins polymerization, different methods of restoration placement were imagined in trying to reduce the bonded to unbonded restoration surface ratio [19]. One of this methods is represented by the oblique layering technique which reduces the contraction forces that occur between opposing walls, and, by that, the cuspal fissures or gap formation [20].

In order to simulate the degradation of composite bond in this study, the aging by thermocycling was used. Different authors suggested different dwell times. These ranged from 4 to $180 \mathrm{~s}$, without any justification. After a careful analysis of more studies, Gale and Darewell [21] noticed wide variations in the thermocycling regimens and concluded that there no rule must be respected when choosing a regimen by the contrary, Rossomando et al. [22] concluded that the dwell time should be of maximum $10 \mathrm{~s}$ in order to be clinically relevant.

One more issue that needs to be mentioned in microleakage studies is related to the scoring systems. The evaluation in these studies, usually uses the observer's interpretation, so the leakage scoring can be considered a semi-measurable method [23,24]. In addition, various studies mention that dye leakage in different sections of the restoration may show significant differences $[25,26]$. For this reason, it is mandatory to assess the leakage on more just one section from a tooth, in order to increase the accuracy of the study.

For the moment, there are no quantitative methods that can be applicate for the microleakage determination. The microleakage was measured through quantification in the present study.

The method within stereomicroscopic studies is based on the interpretation of the dye leakage on the cavity walls and is defined as a semi-quantitative approach where the leakage is calculated solely at the surface where the section is made [27].

The present study showed that the marginal microleakage was present in both groups, but in different proportions. Even if the differences were not statistically validated, the teeth restored by oblique layering technique showed lower scores compared to those restored by horizontal layering technique. Therefore, this difference can be due to the different layering technique that was used. 
The results are in agreement with Sarfi et al. [14] and Ghavamnasiri et al. [28] who concluded that, regarding the microleakage, there are not any differences between different layering techniques. In addition, similar results were obtained by Santhosh et al. [29] and Usha et al. [30]. By the contrary, Eakleet et al. [31] found that the oblique layering technique had the most leak-free margins when the proximal box ended on enamel.

Oliveira et al. [32] showed that there are no significant differences between the level of shrinkage stress at the tooth-restoration interface when these two techniques of resin composite placement are used. However, Versluis et al. [33] observed that the highest degree of cusp flexion occurs in the horizontal technique followed by the oblique one. Other studies, like those that belong to Kwon et al. [34] or de Park et al. [35] found that the incremental layering technique leads to a significantly less cuspal deflection when compared to bulk filling technique, however, when comparing the horizontal with oblique layering techniques, there is no significant difference.

AFM seemed to be a useful tool for the assessment of marginal adaptation. The AFM uses a software with great mathematical accuracy for the mapping and characterization of surfaces [36,37] and provides 3D high-resolution offering quantitative data related to the length of marginal gaps. Furthermore, the samples to be investigated by AFM do not require special preparations (such as metallization or fixing) which reduces the occurrence possibility of the artifacts that could affect the analysis [36,38].

According to SEM images analysis of the Score 0 samples, the increased adhesion of the composite to the dental structures can be explained by the existence of a clearly defined hybrid layer on the entire interface in all specimens treated in this study. The granular appearance of the adhesive is due to the $\mathrm{SiO}_{2}$ filling content of the adhesive. The formation of a homogeneous hybrid layer means the closure of any communication path between the pulp chamber and the outside, meaning a perfect sealing of the dentinal wound.

Regarding the SEM images analysis of the samples with a score higher than zero, the cracks can be due to the low bond strength at the composite/dental structure interface, which could not face the resin polymerization shrinkage and could not provide an adequate interfacial seal for these samples. These issues can, also, be due to the drying of the tooth sections in the air while manipulating or the dehydration under vacuum during SEM analysis. However, because these gaps or cracks were noticed mainly when horizontal layering technique was used and since all samples were treated in the same way, they can be attributed to the low adhesion between the composite and dental structure.

It is not a novelty that the hybrid layer is the most important element in adhesivedentin bond strength $[39,40]$. It is formed by resin that covers the collagen fibrils. The bonding agent needs to uniformly penetrate the collagen system and be completely polymerized in order to generate high bond strength.

Considering the EDX analysis, the silica and aluminum in the adhesive layer and dentin is the result of the presence of nanofiller in their composition, and further confirms that resin tags were produced by the adhesive systems. EDX analysis also revealed increased quantities of silica and aluminum in the composite structures, suggesting the presence of an inorganic filler in the material.

The most of the composites contain methacrylate resins and the polymerization process is initiated by light. Almost the whole polymerization process occurs in the first minutes after irradiation [41]. In order to ensure the polymerization for all the restorative material, increments of maximum $2 \mathrm{~mm}$ thickness are applied, so the light will penetrate and activate the polymerization in depth [42].

To assess the efficacy of polymerization in composite resins, some laboratory analysis are documented in the literature. Fourier transform infra-red spectroscopy (FTIR) is one of them and it represents a technique that compares the vibration bands of the residual unpolymerized methacrylate $C=C$ stretching mode at $1640 \mathrm{~cm}^{-1}$ to the aromatic $\mathrm{C}=\mathrm{C}$ stretching mode at $1610 \mathrm{~cm}^{-1}$ in order to evaluate the degree of conversion. FTIR spectroscopy is based on the absorption of radiation in the infrared frequency range in 
accordance with the molecular vibrations of the functional groups contained in the polymer chain [43].

In the present study, FTIR was used to observe the polymerization characteristics of a composite resin when is used in two different ways. In both situations, similar spectra curves can be observed, which indicates a similar mechanism is prevailing, based exclusively upon the relative amounts of resin and filler and is, probably, explained by a restricted mobility of the reactants.

The horizontal layering technique, in which each successive layer is in contact with the pulpal wall or the previously placed layer and all axial walls, produces high values of $C$ factor. Thus, this technique shows the highest shrinkage stress during polymerization [29].

When the oblique layering technique is used, successive layers of triangular shape are placed, so the $C$ factor and the distortion of the cavity walls are reduced [44]. Due to the shape of the layers, they cover less of the wall surfaces than in horizontal layering. This leads to less stress at the tooth/restoration interface [32].

This may explain the difference in the degree of dye penetration observed in the two groups. The present study shows that the specimens in the first group perform better than the teeth in the second group.

In this study, each composite layer was light-cured exclusively from the occlusal aspect. The light from the light-curing lamp initially acts on the outer layer of the resin. This leads to the traction of the pulpal wall, thus increasing the level of stress in this area [33].

Our results are consistent with the results of previous studies, like Derhami et al. [45], Hilton et al. [46] and Demarco et al. [47], who established the margins along the occlusal cavities can be less exposed to microleakage due to the thickness of the enamel in that region. Polymerization shrinkage does not cause important problems when restorations are located only in enamel, because enamel is a solid substrate for bonding [48]. Bonding to the dentin has more deficiencies due to the tubular structure and intrinsic wetness [49].

\section{Conclusions}

A strong and durable bond of the composite to both enamel and dentin is the secret for clinical success when speaking of restorative dentistry. None of the composite layering technique used in this study was able to eliminate marginal microleakage. Even if it seemed that the oblique technique showed a better adaptation of the restorative material to the dental tissue, the statistical analysis did not confirm that. The composite layering technique still remains an open quest and, moreover, in vivo studies should be designed in order to assess microleakage in real conditions of the oral environment.

Author Contributions: Conceptualization, A.M.C. and M.M.; methodology, C.S., O.P.; software, I.P., L.B.T.; validation, R.M.C., A.M., and A.G.D.; formal analysis, M.P.; investigation, A.M.C., M.M., R.M.C.; resources, D.I.R.; data curation, A.M.C., C.S.; writing—original draft preparation, R.M.C., D.I.R., O.P., A.G.D.; writing—review and editing, M.P., A.M.; visualization, D.I.R., I.P., L.B.T.; supervision, A.M.C., M.M.; project administration.; funding acquisition, O.P., M.P., M.M.; A.G.D., A.M., D.I.R. and O.P. have equal contribution to the work reported with A.M.C. All authors have read and agreed to the published version of the manuscript.

Funding: This research received no external funding.

Institutional Review Board Statement: Not applicable.

Informed Consent Statement: Not applicable.

Data Availability Statement: Not applicable.

Acknowledgments: The authors of the present paper acknowledge the Research Center in Physical Chemistry "CECHIF" of Babes Bolyai University for AFM assistance.

Conflicts of Interest: The authors declare no conflict of interest. 


\section{References}

1. Shih, W.Y. Microleakage in different primary tooth restorations. J. Chin. Med. Assoc. 2016, 79, 228-234. [CrossRef] [PubMed]

2. Martin, E. Adaptation and micro-leakage of composite resin restorations. Aust. Dent. J. 1984, 29, 362-370. [CrossRef]

3. Chisnoiu, R.; Pastrav, O.; Delean, A.; Prodan, D.; Boboia, S.; Moldovan, M.; Chisnoiu, A. Push-out Bond Strengths of Three Different Endodontic Sealers A comparative study. Mater. Plast. 2015, 6, 239-242.

4. Meiers, J.C.; Kresin, J.C. Cavity disinfectants and dentin bonding. Oper. Dent. 1996, 21, 153-159. [PubMed]

5. Chisnoiu, R.; Moldovan, M.; Păstrav, O.; Delean, A.; Chisnoiu, A.M. The influence of three endodontic sealers on bone healing: An experimental study. Folia Morphol. 2016, 75, 14-20. [CrossRef]

6. Unterbrink, G.L.; Liebenberg, W.H. Flowable resin composites as "filled adhesives": Literature review and clinical recommendations. Quint Int. 1999, 30, 249-257.

7. Klaff, D. Blending Incremental and Stratified Layering Techniques to Produce an Aesthetic Posterior Composite Resin Restoration with a Predictable Prognosis. J. Esthet. Restor. Dent. 2001, 13, 101-113. [CrossRef]

8. Matei, R.I.; Todor, L.; Cuc, E.A.; Popescu, M.R.; Dragomir, L.P.; Rauten, A.M.; Porumb, A. Microscopic aspects of junction between dental hard tissues and composite material depending on composite insertion: Layering versus bulk-fill. Rom. J. Morphol. Embryol. 2019, 60, 133-138.

9. Ferracane, J.L.; Lawson, N.C. Probing the hierarchy of evidence to identify the best strategy for placing class II dental composite restorations using current materials. J. Esthet. Restor. Dent. 2021, 33, 39-50. [CrossRef]

10. Pardo Díaz, C.A.; Shimokawa, C.; Sampaio, C.S.; Freitas, A.Z.; Turbino, M.L. Characterization and Comparative Analysis of Voids in Class II Composite Resin Restorations by Optical Coherence Tomography. Oper. Dent. 2020, 45, 71-79. [CrossRef]

11. Majety, K.K.; Pujar, M. In vitro evaluation of microleakage of class II packable composite resin restorations using flowable composite and resin modified glass ionomers as intermediate layers. J. Conserv. Dent. 2011, 14, 414-417. [CrossRef]

12. Chisnoiu, R.M.; Moldovan, M.; Prodan, D.; Chisnoiu, A.M.; Hrab, D.; Delean, A.G.; Muntean, A.; Rotaru, D.I.; Pastrav, O.; Pastrav, M. In-Vitro Comparative Adhesion Evaluation of Bioceramic and Dual-Cure Resin Endodontic Sealers Using SEM, AFM, Push-Out and FTIR. Appl. Sci. 2021, 11, 4454. [CrossRef]

13. Jafari, T.; Alaghehmad, H.; Moodi, E. Evaluation of cavity size, kind and filling technique of composite shrinkage by finite element. Dent. Res. J. 2018, 15, 33-39.

14. Sarfi, S.; Neerja, S.; Ekta, G.; Dildeep, B. Comparing microleakage inSilorane based composite and nanofilled composite using different layering techniques in class I restorations: An in vitro study. IAIM 2017, 4, 23-32.

15. Sahu, D.; Somani, R. Comparative evaluation of microleakage of various glass-ionomer cements: An in vitro study. Int. J. Prev. Clin. Dent. Res. 2018, 5, 17-20.

16. Youssef, M.N.; Youssef, F.A. Effect of enamel preparation method on in vitro marginal microleakage of a flowable composite used as pit and fissure sealant. Int. J. Paediatr. Dent. 2006, 16, 342-347. [CrossRef]

17. Paromita, M.; Abiskrita, D.; Utpal, K.D. Comparative evaluation of microleakage of three different direct restorative materials (silver amalgam, glass ionomer cement, cention N), in Class II restorations using stereomicroscope: An in vitro study. Indian J. Dent. Res. 2019, 30, 277-281.

18. Celik, C.; Bayaktar, Y.; Ozdemir, B.E. Effect of Saliva Contamination on Microleakage of Open Sandwich Restorations. Acta Stomatol. Croat. 2020, 54, 273-282. [CrossRef] [PubMed]

19. Moezyzadeh, M.; Kazemipoor, M. Effect of different placement techniques on microleakage of class V composite restorations. J. Dent. 2009, 6, 121-129.

20. Tsujimoto, A.; Jurado, C.A.; Barkmeier, W.W.; Sayed, M.E.; Takamizawa, T.; Latta, M.A.; Miyazaki, M.; Garcia-Godoy, F. Effect of Layering Techniques on Polymerization Shrinkage Stress of High- and Low-viscosity Bulk-fill Resins. Oper. Dent. 2020, 45, 655-663. [CrossRef]

21. Gale, M.S.; Darvell, B.W. Thermal cycling procedures for laboratory testing of dental restorations. J. Dent. 1999, 27, 89-99. [CrossRef]

22. Rossomando, K.J.; Wendt, S.L., Jr. Thermocycling and dwell times in microleakage evaluation for bonded restorations. Dent. Mater. 1995, 11, 47-51. [CrossRef]

23. Weinmann, W.; Thalacker, C.; Guggenberger, R. Siloranes in dental composites. Dent. Mater. 2005, 21, 68-74. [CrossRef]

24. Hilton, T.J.; Schwartz, R.S.; Ferracane, J.L. Microleakage of four Class II resin composite insertion techniques at intra oral temperature. Quint. Int. 1997, 28, 135-144.

25. Neiva, I.F.; de Andrada, M.A.C.; Baratieri, L.N.; Monteiro, S.; Ritter, A.V. An in vitro study of the Effect of Restorative Technique on Marginal Leakage in Posterior Composites. Oper. Dent. 1998, 23, 282-289.

26. Yap, A.U.J.; Wang, H.B.; Siow, K.S.; Gan, L.M. Polymerization Shrinkage of Visible-Light-Cured Composites. Oper. Dent. 2000, 25, 98-103.

27. Albers, H.F. Tooth-Colored Restoratives. Principles and Techniques; BC Decker Inc.: London, UK, 2002; pp. 90-93.

28. Bagis, Y.H.; Baltacioglu, I.H.; Kahyaogullari, S. Comparing Microleakage and the Layering Methods of Silorane-based Resin Composite in Wide Class II MOD Cavities. Oper. Dent. 2009, 34, 578-585. [CrossRef]

29. Santhosh, L.; Bashetty, K.; Nadig, G. The influence of different composite placement techniques on microleakage in preparations with high C-factor: An in vitro study. J. Conserv. Dent. 2008, 11, 112-116. [CrossRef] 
30. Usha, H.; Kumari, A.; Mehta, D.; Kaiwar, A.; Jain, N. Comparing microleakage and layering methods of silorane-based resin composite in class V cavities using confocal microscopy: An in vitro study. J. Conserv. Dent. 2011, 14, 164-168.

31. Eakle, W.S.; Ito, R.K. Effect of insertion technique on microleakage in mesio-occlus-odistal composite resin restorations. Quint. Int. 1990, 21, 117-123.

32. Oliveira, K.M.; Lancellotti, A.C.; Ccahuana-Vasquez, R.A.; Consani, S. Influence of filling technique on shrinkage stress in dental composite restorations. J. Dent. Sci. 2013, 8, 53-60. [CrossRef]

33. Verluis, A.; Douglas, W.H.; Cross, M.; Sakaguchi, R.L. Does an Incremental Filling Technique Reduce Polymerization Shrinkage Stresses? J. Dent. Res. 1996, 75, 871-878. [CrossRef] [PubMed]

34. Kwon, Y.; Ferracane, J.; Lee, I.B. Effect of layering methods, composite type and flowable liner on the polymerization shrinkage stress of light cured composites. Dent. Mater. 2012, 28, 801-809. [CrossRef] [PubMed]

35. Park, J.; Chang, J.; Ferracane, J.; Lee, I.B. How should composite be layered to reduce shrinkage stress: Incremental or bulk filling? Dent. Mater. 2008, 24, 1501-1505. [CrossRef]

36. Batista, L.H.C.; Silva, J.G.; Silva, M.F.A.; Tonholo, J. Atomic force microscopy of removal of dentin smear layers. Microsc. Microanal. 2007, 13, 245-250. [CrossRef]

37. Kakaboura, A.; Fragouli, M.; Rahiotis, C.; Silikas, N. Evaluation of surface characteristics of dental composites using profilometry, scanning electron, atomic force microscopy and gloss-meter. J. Mater. Sci. Mater. Med. 2007, 18, 155-163. [CrossRef]

38. Botta, A.C.; Duarte, S.; Paulin Filho, P.I.; Gheno, S.M. Effect of dental finishing instruments on the surface roughness of composite resins as elucidated by atomic force microscopy. Microsc. Microanal. 2008, 14, 380-386. [CrossRef]

39. Borges, A.; Hasna, A.A.; Matuda, A.G.N.; Lopes, S.R.; Mafetano, A.P.V.P.; Arantes, A.; Duarte, A.F.; Barcellos, D.C.; Torres, C.R.G.; Pucci, C.R. Adhesive systems effect over bond strength of resin-infiltrated and de/remineralized enamel. F1000Research 2019, 11, 1743. [CrossRef]

40. Yamauchi, K.; Tsujimoto, A.; Jurado, C.A.; Shimatani, Y.; Nagura, Y.; Takamizawa, T.; Barkmeier, W.W.; Latta, M.A.; Miyazaki, M. Etch-and-rinse vs self-etch mode for dentin bonding effectiveness of universal adhesives. J. Oral Sci. 2019, 27, 549-553. [CrossRef]

41. Stansbury, J.W. Dimethacrylate network formation and polymer property evolution as determined by the selection of monomers and curing conditions. Dent. Mater. 2012, 28, 13-22. [CrossRef]

42. Pilo, R.; Oelgiesser, D.; Cardash, H.S. A survey of output intensity and potential for depth of cure among light-curing units in clinical use. J. Dent. 1999, 27, 235-241. [CrossRef]

43. Moraes, L.G.P.; Rocha, R.S.F.; Menegazzo, L.M.; Araújo, E.B.; Yukimito, K.; Moraes, J.C.S. Infrared spectroscopy: A tool for determination of the degree of conversion in dental composites. J. Appl. Oral Sci. 2008, 16, 145-149. [CrossRef] [PubMed]

44. Chandrasekhar, V.; Rudrapati, L.; Badami, V.; Tummala, M. Incremental techniques in direct composite restoration. J. Conserv. Dent. 2017, 20, 386-391. [PubMed]

45. Derhami, K.; Colli, P. Microleakage in Class 2 composite restorations. Oper. Dent. 1995, 20, 100-105. [PubMed]

46. Poggio, C.; Chiesa, M.; Scribante, A.; Mekler, J.; Colombo, M. Microleakage in Class II composite restorations with margins below the CEJ: In vitro evaluation of different restorative techniques. Med. Oral Patol Oral Cir Bucal. 2013, 18, e793-e798. [CrossRef] [PubMed]

47. Demarco, F.F.; Ramos, O.L. Influence of different restorative techniques on microleakage in class II cavities with gingival wall in cementum. Oper. Dent. 2001, 26, 253-259. [PubMed]

48. Roberson, T.M.; Heymann, H.O.; Ritter, A.V. Introduction to Composite Restorations. Sturdevant's Art E Science Operative Dentistry, 4th ed.; Mosby: St. Louis, MI, USA, 2002; pp. 473-499.

49. Eick, J.D.; Cobb, C.M.; Chappel, R.P.; Spencer, P.; Robinson, S.J. The dentinal structure: Its influence on dentinal adhesion. Part I. Quint. Int. 1991, 22, 967-977. 